\title{
Symphalangism with multiple anomalies of hands and feet
}

INSERM

\section{Source}

INSERM. (1999). Orphanet: an online rare disease and orphan drug data base.

Symphalangism with multiple anomalies of hands and feet. ORPHA:3246

Symphalang ism with multiple anomalies of hands and feet is a rare, genetic, congenital limb malformation disorder characterized by bilateral symphalang ism of hands and feet associated with cutaneous syndactyly of digits II-V, unilateral or bilateral brachydactyly type D (i.e. short, broad terminal phalanges of the thumbs), clinodactyly of fifth toes and/or mild hypoplasia of the thenar and hypothenar eminences. There have been no further descriptions in the literature since 1981. 